DOI https://doi.org/10.18551/rjoas.2017-08.13

\title{
INNOVATIVE METHODS FOR WORK PROCESS DESIGN IN A HIGH TECHNOLOGY ENTERPRISE
}

\author{
Novikov S.V., Candidate of Economic Sciences \\ Moscow Aviation Institute (National Research University), Moscow, Russia \\ E-mail: ncsrm@mail.ru
}

\begin{abstract}
The article presents conceptual framework of work flow structure in a high-technology enterprise of science-based industries. Direct correlation of technology lag in work management level is considered. The article suggests new methods for work flow design based on organic connection of scientific and technological achievements with the contents, form, conditions and methods of work process structure.
\end{abstract}

\section{KEY WORDS}

High-technology manufacturing, methods for work process structuring, science-based industry, innovations in engineering, work process design.

In modern society, work process should be based on science and best practices achievements, on the connection between people and technology. This is due to the fact that the content of any work process is determined by a specific technology process and that the trends in scientific and technological progress determine the main changes in the content of the work process and, consequently, in human work activity. Due to the fact that overall trends of scientific and technological progress are related to some particular conditions of work process (somehow or other affecting a human body), a person is able to change a lot in the technological process itself and in the work and manufacturing structure. Being an important element of production force, technology is developing rather fast. However, only following the adoption of the new technology it is possible to develop the form, methods and conditions for the work process structure of the employees, working with the equipment, and this development process is not automatic. There are many examples of the lagging behind in the rapid pace of technological progress at the appropriate level of the work process structuring. On the basis of this inconsistency occur contradictions and imbalances in the development of technological progress, and the main direction of scientific and technological progress is the integrated automation and integration of production processes related to the introduction of advanced equipment (numerically controlled machines, flexible production modules, etc.) and automated management systems. Such progress tends to eliminate completely or partially parts of non-mechanized manual labour and to cause significant shifts in the structure of work process. By drastically reducing the use of manual labour, automation and integration create new types of work that require a thorough knowledge of production technology that is intellectually acquired but still involved in physical efforts. Thus, by improving the means of production and technology, people are also going through a famous self-improvement process.

Improving the nature and content of work in a context of production intensification requires continuous improvement in the organization of jobs and the design of work processes, taking into account technical, economic, psycho-physiological and social factors. Therefore, in order to increase efficiency in production, there is a need to organically link advances in scientific and technological progress with the content, forms, conditions and methods of the work structuring. It is impossible to turn production on the path of overall intensification, while preserving old organizational forms of work. The creation and largescale introduction of innovative technology, modernization of funds and production continuously alter the working environment, causing significant shifts in the structure of the work processes.

Employees have drastically different work process structures and functions. However, 
any work process has some amount of work functions that require a person's physical, emotional and intellectual effort. In light of all of the above, it is possible to outline the following work process structures: predominantly physical labour; predominantly emotionally stressful work; combining physical and emotionally stressful work.

While forming the best possible structure of the work process, which ensures the most appropriate use of the equipment, working time, production skills and creativity of each member of the team special attention should be paid to the design method independent of its structure.

The design of work processes refers to the creation of a working environment in which work processes are most efficient and least tedious. This is achieved through the selection of a suitable work position, the best possible external and internal layout of the workplace, the necessary equipment, the rational placement of the instrument and the use of best practices and working methods. The economic literature is not sufficient from the point of view of work process design. As a rule, most authors confine themselves to work process structure analysis and describe work process design as a design of individual components of the work process or parts of the work process project. This does not take into account the changes in the composition of the work process, its relationship and interaction, or social demands. The presenter is considered to be the holder of the necessary capacity. With regard to the work process design methods, the analysis of literature and methodological recommendations on the subject has shown that theory and practice now suggest the use of the following methods: analytic and regulatory; balancing; analytic and logical; line graphs; mass service theory; network diagram (graph); mock up.

Analytic and regulatory design method consists in setting the parameters of work processes on the basis of the already existing work regulations, equipment and other work conditions. This method, on the one hand, reduces the labour-intensive of designing of the constituent elements of the work process, since it eliminates the need for specific observations to be made in the workplace, but on the other hand all calculations of the parameters of the work process are approximate and far from the specific work conditions. Moreover, the analytic and regulatory method does not allow for the entire structure of the work process to be covered because of the limited number of work standards applied in practice. For example, there are no regulations on social aspects of human work. Accordingly, it may be applied only in a limited manner (mainly at the stage of production development of new types of products).

Balancing method consists in defining the parameters of the work process on the basis of experience in designing similar work processes considering production and technical conditions of a particular workspace. This method does not require special observations and sometimes makes it difficult to identify bottlenecks in the designed composite elements of the work process and, consequently, to increase the efficiency of workers.

The analytic and logical method is based on the monitoring of the existing work process in the workplace, followed by its comparison with a similar work process of the advance worker to identify ways of saving of working hours on the negative parameters of the work process being analyzed. In this case, the design of the work processes is limited to the development of appropriate recommendations to improve the negative parameters of the work process. In addition, the absence of a regulatory framework in this method (as well as in the balancing method) carries the potential for subjectivity in optimizing of design elements of the work process, which has a certain impact on work efficiency performance.

The methods of line graphs and mass service theory are based on the application of mathematical methods. However, these methods cannot describe the entire structure of the work process because of the multiplicity of factors that cannot be mathematically formalized, because they are based on qualitative information. Such factors include, for example, social factors. This leads to the fact that only some factors that influence the work process content are mathematically described in the design process; the designed constituent elements of the work process are not objective enough and are to a certain extent detached from an individual.

The network diagram method is used in the design of the work processes primarily to 
determine the total of succession or parallel work performed to implement the technological process. The difficulty of using this method is that the work process, because of its complexity and dynamism, is difficult to fix in a "sculpturesque" manner.

The mock-up method is based on an ergonomic approach to the design of the work process. The method only allows analysis of the organization of jobs.

It should be noted that the above-described methods of design of work processes aimed at improving the organization of work in enterprises have been applied mainly at a time when the level of technical sophistication of work processes has been relatively low and technological upgrading has been slow. In the context of scientific and technological progress acceleration, these methods cannot be used as universal. Due to their shortcomings, which can be summarized as follows. The existing methods basically allow for the design of the work process, not as a whole, but as scattered parts of the process. This results in a complete or partial mismatch of the constituent parts of the work process in the implementation phase, requiring additional work to fillet the parts and, consequently, additional capital investment. Eventually, this is reflected in an increase in the adoption time of the new product, which is undesirable in modern business environments.

As is well known, the production process and the related work processes in the context of scientific and technological progress are very dynamic and require constant improvement; however, the existing design methods do not take into account the dynamism of these systems, but rather build a model of the work process discretely, only for a certain amount of time. The latter sometimes results in the inadequacy of the designed work process and the production environment in the implementation phase.

It should be noted that the typical work process designs, which form the basis of typical labour structure designs, were developed by sectoral institutions in 1980-1988 in accordance with the above design methods and have similar disadvantages. New developments in this field are few in number and are mostly found in enterprises where lean manufacturing systems are in place. This leads to under-coverage of the elements of the work process and affects the economic and social performance of enterprises. Thus, the author's analysis of the design of work processes in the aviation industry over the past three years has revealed that the existing deficiencies in the design and structuring of work processes lead to: low amount of employees holding a second job. Thus, by the end of 2016, only 12 per cent of all workers had a side job, with only 5.8 per cent having three or more occupations; relative increase in the number of workers performing manual work, having access to machines and machinery equipment compared to the number of workers performing similar work by means of machinery to monitor and repair the machines. In this case, fewer performers are moved out of the process than there are involved (by the mechanization and the automation of the work processes); increase in the number of workers employed in manufacturing, production dept., and work with harmful working conditions; significant loss of time; every worker is not involved in the production 12 to 15 days annually; reduce in the level of capital productivity; lagging of the growth rate of labour productivity from the growth of its capital-to-labour ratio.

Thus, the issue of choosing a method of designing work processes that would have the merits of all the methods discussed above is now becoming relevant. And could serve as a universal basis for the design of work processes of any production and would be based on the principles of an integrated multidimensional approach, with a view to the organic connection of technological and economic, psycho-physiological and social aspects of human work. That is, the work process, in the diversity of the connections, functions, goals and objectives between its constituent parts during design process, must be seen as a single complex social and economic process.

\section{REFERENCES}

1. Novikov S.V., Meshankov D.V. Present-day personnel policy implementation in Russia: challenges and risks. Competitiveness in a globalized world: economy, science, technology. 2017. No. 3-3 (34). Pp. 113-115. 
2. Tikhonov A.I. Institutional aspects of state personnel policy in Russia. Management and business administration. 2017. No. 2. Pp. 25-32.

3. Nikolaev A.V., Tikhonov A.I., Novikov S.V. Civil statesmen professional activity efficiency assessment. Russian technology journal. 2014. No. 4 (5). Pp. 284-295.

4. Tikhonov A.I., Kraev V.M. Action against fraud in staff management. Teaching material / Stavropol, 2017.

5. Korzhueva L.M., Novikov S.V. The development of regulatory framework and background for forming an innovative educational complex. Collected book: Post-crisis outlining of innovative processes. Ed. by R.M. Nizhegorodtseva. 2010. Pp. 237-241.

6. Korzhueva L.M., Novikov S.V. Improving the efficiency assessment system of educational complex innovative target program. MAl works. 2010. No. 41. P. 25.

7. Gusakov A.G., Novikov S.V. Balanced system problems of motivating personnel in Russian enterprises. Collected book: Economy and management matters and issues in a present-day world. Collection of research papers summarizing the results of the international academic and research conference. 2016. P. 264-266.

8. Semina A.P., Fedotova M.A., Tikhonov A.I. Personnel training in present-day companies: problems and new fields. Moscow economic journal. 2016. No. 3. P. 33.

9. Kraev V.M., Tikhonov A.I. Risk management in dealing with personnel. Competitiveness in a globalized world: economy, science, technology. 2016. No. 8-2 (21). pp. 22-25. 